\title{
Porous Sulfonated PVA Microspheres for Controlled Molecules Delivery: A Methylene Blue Study
}

\author{
M. G. Verón ${ }^{1,2}$, L. A. Soria ${ }^{3}$, M. O. Prado ${ }^{1,2}$ \\ 1. Consejo Nacional de Investigaciones Científicas y Técnicas, CONICET. Av. De Los Pioneros 2500, \\ R8402AGP, S. C. de Bariloche, Río Negro, Argentina \\ 2. Centro Atómico Bariloche (CNEA), Av. Ezequiel Bustillo 9500, R8402AGP, S. C. de Bariloche, Río Negro, \\ Argentina \\ 3. Universidad Nacional de Río Negro. Tacuarí 150, R8402AGP, S. C. de Bariloche, Río Negro, Argentina \\ E-mail: maria.gisela.veron@cab.cnea.gov.ar
}

Received: 3 December 2020; Accepted: 6 January 2021; Available online: 10 February 2021

\begin{abstract}
Functionalized PVA microspheres are commonly used as drug carriers in the fields of pharmacy and medicine. With this aim, we obtained and test novel PVA-PVAc-AMPS sulfonated microspheres by free radical suspension polymerization of vinyl acetate (VAc) and 2-acrylamido-2-methyl-1-propanesulfonic sodium salt acid (AMPS), followed by saponification. The microspheres exhibited a porous core-shell structure with excellent sphericity, a mean size of $171 \mu \mathrm{m}$, and elasticity modulus comparable with commercial particles currently used in medical applications. Methylene blue (MB) which has shown similar adherence properties as the cytostatic drug doxorubicin was used as a model drug to study the drug loading/release characteristics of the sulfonated microspheres prepared in this work. $20.7 \mathrm{mg} \mathrm{g}^{-1} \mathrm{MB}$ per gram of microspheres was the maximum adsorption capacity in two hours using UV-Vis absorption spectroscopy. The experimental data on adsorption were well described by the pseudo-second order kinetic model. The in vitro release profile of loaded MB microspheres showed rapid desorption in the first hour followed by slower MB release, reaching 8.6\% elution at four hours. The diffusion process was found to be dominant in the MB desorption from the PVA-PVAc-AMPS microspheres.

Keywords: Poly(vinyl alcohol) (PVA); Core-shell polymers; Biopolymers; Copolymerization; Drug delivery systems; Methylene blue.
\end{abstract}

\section{Introduction}

Ion exchange microspheres (IEM) are commonly used in fields related to pharmacy and medicine, particularly in the controlled administration of medications, diagnosis and administration of anticancer drugs [1-5]. These particles consist of a polymer solid phase containing integrated ionic moieties with high affinity for oppositely charged ions. When IEM are mixed with a fluid, the ions in the fluid can be exchanged with the counterions of the polymer solid phase and physically removed from it [6]. This process is controlled by factors such as $\mathrm{pH}$, temperature, ionic strength of the release medium and drug properties such as molar mass and charge density. Furthermore, the release rates can be controlled by the polymer structure such as the degree of crosslinking, and also by the size of the particles [1,6-8].

Within this type of microspheres, IEM containing PVA have gained considerable importance in the medical field, and their use is directly related to the qualities of this polymer: non-toxic, biocompatible, good elasticity and swelling capacity, high compressibility and effective chemical resistance to acids and bases [1,3]. On the other hand, PVA contains in its structure abundant reactive and chemically modifiable -OH groups. This has allowed the functionalization of the microspheres, in some cases with positively or negatively charged groups, which gives them the ability to sequester drugs with opposite charge by ionic interaction $[5,6,8]$. However, PVA cannot be obtained by direct polymerization of the vinyl alcohol monomer due to the tautomerism of the vinyl alcohol molecules, and is generally obtained by saponification of a poly(vinyl ester), such as poly(vinyl pivalate) and poly (vinyl acetate), PVAc, the latter being the most common precursor of PVA. This method has been reported by several authors in the preparation of core-shell PVAc-PVA microspheres with suitable characteristics for their application in transarterial embolization procedures (TAE) [9-13]. In this topic, embolic microspheres of PVA modified with sulfonate groups or sodium acrylate have been developed, and are known as DC Beads and Hepasphere, respectively $[1,14,15]$. These functional groups give the microspheres a negative charge and the ability to capture and release positively charged drugs such as Doxorubicin and Irinotecan through ionic interaction. This procedure is known as chemoembolization and today it is considered a first-line therapy for the treatment of 
hepatocellular carcinoma [1,14-18]. Currently DC Beads are the most widely used microspheres. Its synthesis method consists of the preparation of a macromer based on PVA and N-acryloyl-aminoacetaldehyde (NAAADA) which is subsequently copolymerized with 2-acrylamido-2 methylpropanesulfonate sodium salt (AMPS), the monomer that confers the sulfonate groups, and hence the negative charge to the microspheres $[8,19,20]$.

In this work we present novel "PVAc-PVA-AMPS" sulphonated PVA microspheres with a view to its application in controlled drug release. A simple synthesis method based on free radical copolymerization of VAc and AMPS, followed by saponification was used. MB was chosen as a model drug, not only because it has a positive charge under physiological conditions as various chemotherapeutic agents, but also because of its use in phototherapy and its recently reported efficacy in the treatment of Alzheimer's disease and other neurodegenerative diseases [21-23].

\section{Experimental section}

\subsection{Materials}

For the microspheres preparation 2-Acrylamido-2-methylpropane sulfonic acid sodium salt solution 50\% (AMPS solution), benzoyl peroxide (BPO, 97\%), poly(vinyl alcohol) (PVA, Mw 578 kg/mol, 85\% hydrolyzed); vinyl acetate (VAc, 99\%, 3-20 ppm of hydroquinone as inhibitor) from Sigma Aldrich were used. Also Methanol (MeOH) from Dorwill, sodium hydroxide ( $\mathrm{NaOH}, 99 \%)$ and hydrochloric acid ( $\mathrm{HCl}, 36.5-38 \%)$ from Cicarelli Laboratories. Simulated body fluid (SBF) was prepared for in vitro MB release assays using the Kokubo protocol [24]. The reagents were the following: sodium chloride $(\mathrm{NaCl}, 99.9 \%)$, sodium sulfate $\left(\mathrm{Na}_{2} \mathrm{SO}_{4}, 99.5 \%\right)$ and calcium chloride $\left(\mathrm{CaCl}_{2}, 99.9 \%\right)$ were supplied by Mallinckodt. Sodium hydrogen carbonate $\left(\mathrm{NaHCO}_{3}, 99.9 \%\right)$ and potassium chloride (KCl, 99.9\%) by Sigma-Aldrich, dipotassium hydrogen phosphate trihydrate $\left(\mathrm{K}_{2} \mathrm{HPO}_{4} .3 \mathrm{H}_{2} \mathrm{O}\right.$, 99.5\%) was supplied by Berna reagents, and Tris-hydroxymethyl aminomethane (TRIS 99.8$100.1 \%$ ) by Merck. Methylene blue used for adsorption/release studies was obtained from Biopack.

The reagents were used without prior purification, and de-ionized water was applied for the polymerization and treatment processes.

\subsection{Methods}

The synthesis of microspheres was carried out taking as reference the methodologies used in the preparation of PVAc-PVA-AMPS films and PVAc-PVA microspheres, with some modifications [25-28,12,13]. The synthesis process is detailed in Figure 1.

Stage 1: VAc and AMPS polymerization

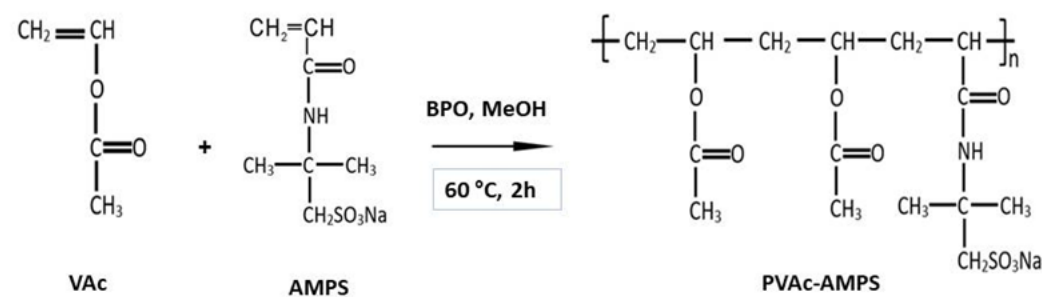

Stage 2: PVAc-AMPS saponification<smiles>CCC(CC(CC(C)C(=O)NC(C)(C)C[18O])OC(C)=O)OC(C)CC(O)CC(CC(CC)C(=O)NC(C)(C)COC(C)(C)C)OC(C)=O</smiles>

Figure 1. Stages of PVA-PVAc-AMPS microsphere synthesis and probable reactions.

In a first stage, the free radical suspension copolymerization of VAc and AMPS was carried out to obtain PVAcAMPS microspheres. It is known that direct copolymerization of AMPS and VAc results in copolymers of inhomogeneous composition due to the low solubility of the monomers during copolymerization [26,27]. To overcome this problem, a mixture of AMPS and MeOH solvent was prepared and added in batches to the VAc containing initiator BPO during the polymerization process. In a second stage, the PVAc-AMPS microspheres 
were subjected to alkaline hydrolysis to replace the acetate groups with hydroxyl groups, thus forming an outer layer of PVA.

\subsubsection{Free-radical suspension copolymerization}

The copolymerization reactions of VAc and AMPS were carried out in a $500 \mathrm{~mL}$ glass reactor at $70{ }^{\circ} \mathrm{C}$ under a nitrogen flux generating an inert atmosphere with slight overpressure. The reactor was provided with a reflux condenser connected to a cold bath.

Initially the reactor was fed with $50 \mathrm{~mL}$ of water and $0.04 \mathrm{~g}$ PVA was added as suspending agent. The mixture was heated at $90{ }^{\circ} \mathrm{C}$ for one hour to achieve dissolution of the PVA then the temperature was reduced to $70{ }^{\circ} \mathrm{C}$.

A mixture of $8 \mathrm{~mL}$ AMPS and $12 \mathrm{~mL} \mathrm{MeOH}$ was prepared and added to a solution containing $0.5 \mathrm{~g}$ of BPO and $24 \mathrm{~mL}$ of VAc. The resulting solution was adjusted to neutral $\mathrm{pH}$ with $0.1 \mathrm{~N} \mathrm{HCl}$ and $0.1 \mathrm{M} \mathrm{NaOH}$, and added to the flask containing the PVA solution at $70{ }^{\circ} \mathrm{C}$. The system was maintained at isothermal conditions with constant agitation of $300 \mathrm{rpm}$ for 60 minutes. $20 \mathrm{~mL}$ of AMPS-MeOH solution was added, maintaining the polymerization reaction for another 60 minutes under the same experimental conditions. The polymerized sample was called PVAc-AMPS microspheres. Then the temperature of the reaction medium was reduced to $30^{\circ} \mathrm{C}$ for the saponification step.

\subsubsection{Saponification}

The saponification process was carried out in the polymerization reactor containing the PVAc-AMPS microspheres. When the temperature decreased to $30^{\circ} \mathrm{C}, 50 \mathrm{~mL}$ of $2 \mathrm{M} \mathrm{NaOH}$ solution were added and the reaction was maintained for two hours at constant temperature, at $300 \mathrm{rpm}$. Agitation was stopped, the supernatant solution was removed and the resulting PVA-PVAc-AMPS microspheres were washed with distilled water several times, filtered under vacuum and allowed to dry at room temperature. Figure 1 shows a schematic of the process of synthesis of the PVA-PVAc-AMPS microspheres

\subsection{Physical characterization}

The chemical structure of the synthesized microspheres was studied by Proton Nuclear Magnetic Resonance ( ${ }^{1} \mathrm{H}$ NMR) and Fourier Transform Infrared Spectroscopy (FTIR). ${ }^{1} \mathrm{H}$ NMR spectrum was obtained on an Advance III HD 600 NMR spectrometer at $600 \mathrm{MHz}$, using DMSO- $d_{6}$ as the solvent. The FTIR spectra were obtained in the wave number range from 3500 to $450 \mathrm{~cm}^{-1}$ during 30 scans, with $4 \mathrm{~cm}^{-1}$ resolution (Paragon 1000, PerkinElmer, USA).

To determine the AMPS content, elemental microanalysis of $\mathrm{N}$ was carried out by combustion at $900{ }^{\circ} \mathrm{C}$, using a Thermo Scientific Flash EA 1112 Nitrogen and Carbon analyzer. These analyses were done at the Regional Bariloche Center, National University of Comahue.

The morphological study of the microspheres was performed by scanning electron microscopy (SEM) using a SEM-FIB Zeiss crossbeam 340 equipment. Samples were covered with a thin layer of gold $15 \mathrm{~nm}$ thick with a Blazers Sputter Coater SCD 050 before analysis.

To determine the size distribution, the diameter of 500 microspheres were measured with a Leica DM 2500 microscope using the sizing tool provided in the analysis software package (Soft Imaging Systems GmbH, Berlin, Germany).

The BET surface area analysis was performed by the Isotope Separation Division of the Bariloche Atomic Center, using a Micromeritics ASAP 2020. The lyophilization method was used as a pre-treatment of the samples to remove the remaining water and solvents, thus avoiding heating during degassing. Using the ImageJ software, and the SEM images, the pore size distribution and the average pore size was obtained.

Elastic modulus of PVA-PVAc-AMPS microspheres was estimed using stress-strain measurements on single microspheres with a cylindrical probe attached to an Instron Materials Testing Systems Model 5567, equipped with a $1 \mathrm{KN}$ force load cell. The samples were immersed in MB solution (100 $\left.\mathrm{mg} \mathrm{L}^{-1}\right)$ for 24 hours. Individual microspheres were removed from the immersion medium and their diameter was measured with a Leica optical microscope. Each microsphere was placed on a flat surface below the probe. The probe was then extended at a speed of $0.1 \mathrm{~mm}$ min-1 and the Force $(\mathrm{F})$-displacement $(\mathrm{H})$ data was recorded. This test was performed on 5 individual microspheres.

To estimate the Young's modulus Hertz's theory was applied, using the equation:

$$
F=\frac{4}{3} \sqrt{R} \frac{E}{\left(1-v^{2}\right)}\left(\frac{H}{2}\right)^{\frac{3}{2}}
$$

where $\mathrm{R}$ is the radius of a bead, $\mathrm{E}$ is the Young's modulus, $\mathrm{H}$ is the displacement and $v$ is the Poisson ratio, for which a value of 0.5 was considered, based on data reported by other authors for PVA hydrogels [29]. The compression force $(\mathrm{F})$ was plotted against the displacement $(H / 2)^{3 / 2}$. The Young's modulus was determined from 
the slope of the initial linear behavior part of the curve, using a least square regression of the plot of $\mathrm{F}$ versus $(H / 2)^{3 / 2}$.

The degree of crystallinity of the microspheres was determined with an XRD Panalytical Empyrean diffractometer, using $\mathrm{CuK} \alpha$ radiation $(\lambda=1.54 \AA)$, and $40 \mathrm{kV} / 30 \mathrm{~mA}$ beam voltage/current. Analyses were performed varying the angle $2 \theta$, from 10 to $90^{\circ}$, with a step width of $0.013^{\circ}$.

Glass transition temperature (Tg) was determined by Differential Scanning Calorimetry (DSC) using a TA Instruments Q2000 DSC. About $5 \mathrm{mg}$ of microspheres were placed, and sealed in aluminum capsules. The samples obtained were cooled to $-20^{\circ} \mathrm{C}$, stabilized for 5 minutes at this temperature and then scanned from -20 to $140{ }^{\circ} \mathrm{C}$ at $10^{\circ} \mathrm{C} \mathrm{min}^{-1}$.

\subsection{Adsorption of MB onto sulfonated microspheres}

To study MB adsorption, the batch equilibrium technique was used. Thus, $0.02 \mathrm{~g}$ of PVA-PVAc-AMPS microspheres was put into a conical flask and $10 \mathrm{~mL}$ of a MB aqueous solution were added. MB concentrations of 5, 25, 50 and100 $\mathrm{mg} \mathrm{L}^{-1}$ were used. The $\mathrm{pH}$ of the initial solution was adjusted to 4.0, 6.0, 8.0 and 10.0 with solutions additions of $0.1 \mathrm{~N} \mathrm{HCl}$ and $0.1 \mathrm{M} \mathrm{NaOH}$ using a $\mathrm{pH}$ meter (Mettler Toledo).

The samples were shaken at 350 rpm for different time intervals (120, 240 and 360 minutes) at room temperature. After adsorption, the adsorbent and the supernatants were separated by filtration. The residual concentration of MB in the supernatant was analyzed using a UV-Vis spectrophotometer by monitoring the absorbance changes at $664 \mathrm{~nm}$. The amount of dye adsorbed per gram of adsorbent $\left(\boldsymbol{Q}_{\boldsymbol{e}}\right)$, and loading efficiency were calculated using equations (2) and (3), respectively:

$$
\begin{gathered}
\qquad \boldsymbol{Q}_{\boldsymbol{e}}=\frac{\boldsymbol{V}}{\boldsymbol{m}}\left(\boldsymbol{C}_{\mathbf{0}}-\boldsymbol{C}_{\boldsymbol{e}}\right) \\
\text { Loading efficiency }(\%)=\frac{C_{0}-C_{e}}{C_{0}} \times 100
\end{gathered}
$$

where $\boldsymbol{C}_{\mathbf{0}}$ and $\boldsymbol{C}_{\boldsymbol{e}}\left(\mathrm{mg} \mathrm{L}^{-1}\right)$ are the initial and equilibrium concentrations of dye solution, respectively; $\mathrm{V}$ is the volume of dye solution and $\mathrm{m}$ is the weight of PVA-AMPS microspheres. All samples were prepared and measured in triplicate.

\subsection{In vitro release of $\mathrm{MB}$ into SBF solution}

The elution profiles of MB from the PVA-PVAc-AMPS microspheres were evaluated in SBF solution at $37^{\circ} \mathrm{C}$. $1000 \mathrm{~mL}$ of SBF were prepared according to the Kokubo protocol [24] and in each experiment $10 \mathrm{~mL}$ of SBF solution were contacted with $0.020 \mathrm{~g}$ of MB loaded microspheres. The samples were maintained at $37^{\circ} \mathrm{C}$, and $\mathrm{MB}$ release was measured at different time intervals between 0.33 and 4 hours by UV-Vis spectroscopy at $664 \mathrm{~nm}$. A standard MB solution at a concentration of $100 \mathrm{ppm}$ was prepared with the extraction medium (SBF) as solvent and was used for quantification purposes.

The amount of MB desorbed as a function of time, was expressed in terms of percentage rate eluted by the equation (4):

$$
\text { Percentage rate eluted }(\%)=\frac{\mathrm{MB} \text { concentration in } \mathrm{SBF} \text { solution }}{\mathrm{MB} \text { concentration in the microspheres }} \times 100
$$

In vitro drug release tests were performed in triplicate.

\section{Results and discussion}

\subsection{Synthesis and Characterization of sulfonated PVA-AMPS microspheres}

Figure 2 shows the ${ }^{1} \mathrm{H}$ NMR spectrum of the PVA-PVAc-AMPS microspheres and the proposed chemical structure for them based on the synthesis method. The peaks at 4.7, 1.75, 1.4 and $1.92 \mathrm{ppm}$ were those of the methine (c), methylene (a, a') and methyl (d) groups of PVA-PVAc chain, respectivamente [11,30], and the peaks at 2.1 and $1.40 \mathrm{ppm}$ could be assigned to the methine (e) and methyl (g) groups of AMPS [31,32].

During the saponification process, the acetate groups are replaced by hydroxyl groups, the methine (b*) signal should appear as a wide peak between 3.44-3.88 ppm, and the methylene peak (a) between 1.2-1.5 ppm.

In our ${ }^{1} \mathrm{H}$ NMR spectrum a weak signal between 1.2-1.5 ppm can be observed, but the broad peak expected between 3.44-3.88 ppm corresponding to the methine bound to the hydroxyl groups was not detected, which suggests a low degree of hydrolysis of the samples after saponification stage. This result is also reflected in the infrared spectra.

Figure 3 shows the FTIR spectra of the microspheres obtained before and after the saponification step: PVAc- 
AMPS (Figure 3A) and PVA-PVAc-AMPS (Figure 3B), respectively. For reference, the infrared spectra of the microspheres without AMPS, before and after saponification: PVAc (Figure 3C) and PVA-PVAc (Figure 3D), respectively, were acquired.

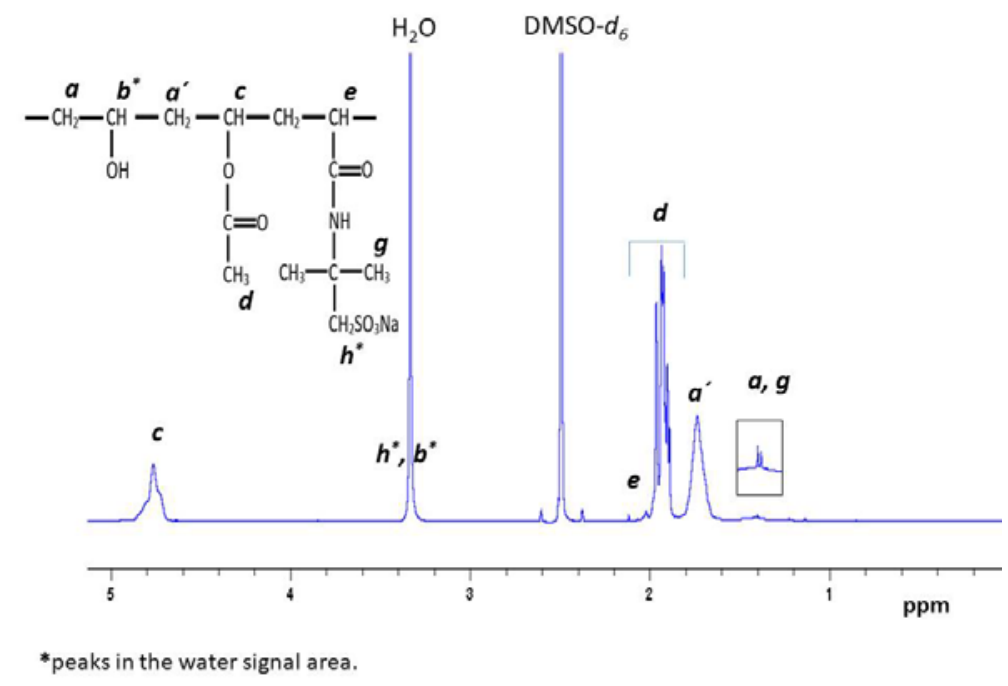

Figure 2. ${ }^{1} \mathrm{H}$ NMR spectrum of PVA-PVAc-AMPS microspheres.

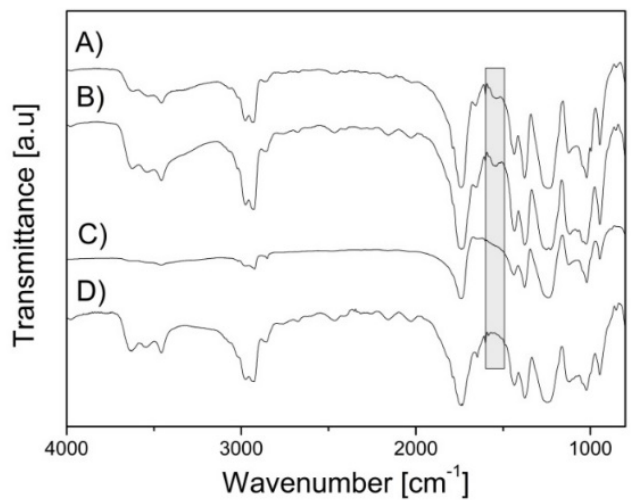

Figure 3. FTIR spectra of A) PVAc-AMPS. B) PVA-PVAc-AMPS. C) PVAc and D) PVA-PVAc microspheres.

In agreement with the literature about PVA-PVAc microspheres, in Figures 3C and 3D can be observed bands vibration characteristics of PVAc can be observed at $2927 \mathrm{~cm}^{-1}$ (stretching $\mathrm{C}-\mathrm{H}$ ), $1740 \mathrm{~cm}^{-1}$ (stretching $\mathrm{C}=\mathrm{O}$ ), $1434 \mathrm{~cm}^{-1}$ ( $\mathrm{CH}_{2}$ asymetric deformation), $1376 \mathrm{~cm}^{-1}\left(\mathrm{CH}_{3}\right.$ asymetric deformation ), $1250 \mathrm{~cm}^{-1}$ (C-H in plane bending), 1122 and $1095 \mathrm{~cm}^{-1}$ (stretching C-O modes), $1045 \mathrm{~cm}^{-1}\left(\mathrm{CH}_{2}\right.$ wagging), $1022 \mathrm{~cm}^{-1}\left(\mathrm{CH}_{2}\right.$ twisting), 946 $\mathrm{cm}^{-1}$ ( $\mathrm{CH}_{3}$ wagging), $793 \mathrm{~cm}^{-1}\left(\mathrm{CH}_{3}\right.$ rocking), 658 and $632 \mathrm{~cm}^{-1}$, in plane and out of plane $\mathrm{C}=\mathrm{O}$ bending, respectively [33-36]. The band at 3550-3200 $\mathrm{cm}^{-1}$ (stretching O-H), 2900-2700 $\mathrm{cm}^{-1}$ (stretching C-H), and 1650$1630 \mathrm{~cm}^{-1}$ (flexion $\mathrm{OH}$ ) can be attributed to PVA [33]. However the strong absorption bands at 1740, 1250 and $1022 \mathrm{~cm}^{-1}$ of the ester, suggest that the microspheres are composed mainly of a large core of PVAc surrounded by a very thin outer PVA layer. These bands are also observed in the spectra of the samples containing AMPS (Figures 3A and 3B), but also a new band between 1500 and $1570 \mathrm{~cm}^{-1}$ centered at $1556 \mathrm{~cm}^{-1}$ was detected, indicating the formation of new bonds. These new bonds can be attributed to $\mathrm{N}-\mathrm{H}$ bending (Amide II) at $1556 \mathrm{~cm}^{-1}$, and $\mathrm{C}=\mathrm{O}$ stretching (Amide I) at $1650 \mathrm{~cm}^{-1}$ [37-39]. The broad band between 3150 and $3720 \mathrm{~cm}^{-1}$ is assigned to the overlap of N-H and O-H stretching vibrations of AMPS and PVA, respectively [40]. The typical bands of the sulfonate groups in the $1000-1250 \mathrm{~cm}^{-1}$ region, corresponding to the symmetric and asymmetric S-O stretching and C-S stretching around $621 \mathrm{~cm}^{-1}$ could not be observed due to the superposition of the PVA-PVAc bands [38-41]. However, S was detected by Energy Dispersive Spectroscopy chemical analysis (Figure 4).

This result confirms that $\mathrm{S}$ is present in the microspheres composition, being AMPS the only S source [37-39]. Other indicator of the AMPS monomer content in the microspheres was determined by N elemental microanalysis. It resulted in $0.15 \pm 0.02 \mathrm{w} / \mathrm{w} \%$ total nitrogen. From the latter, we estimate the amount of AMPS in the microspheres, since AMPS was the only reagent that contained nitrogen. Using a value of 229.23 atomic mass 
units for the AMPS molar mass, we obtain a value of $2.44 \pm 0.02 \mathrm{w} / \mathrm{w} \%$ AMPS content. This value is within the range reported by Moritani et al. and Vicari in the preparation of VAc and AMPS films [27,28], suggesting that the parameters of each stage of the synthesis process were adequate.

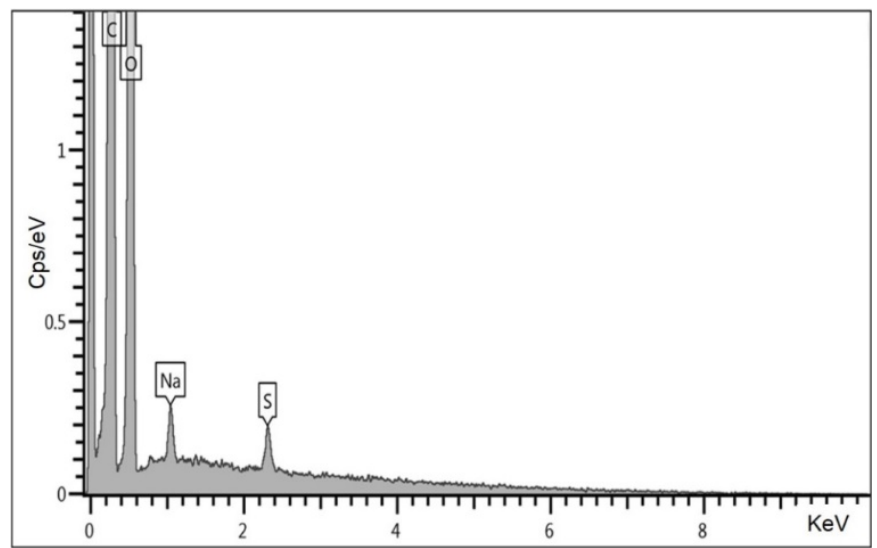

Figure 4. EDS analysis of PVA-PVAc-AMPS microspheres.

The surface morphology of the PVA-PVAc-AMPS microspheres was investigated by SEM. The samples revealed a spherical morphology with an average diameter of $171 \mu \mathrm{m}$ (Figures 5A and 5B, respectively). In addition, a highly porous surface can be distinguished in the detail of Figure 5A. Previously we have observed porosity in PVA-PVAc microspheres obtained by the free radical polymerization method, followed by saponification [42].
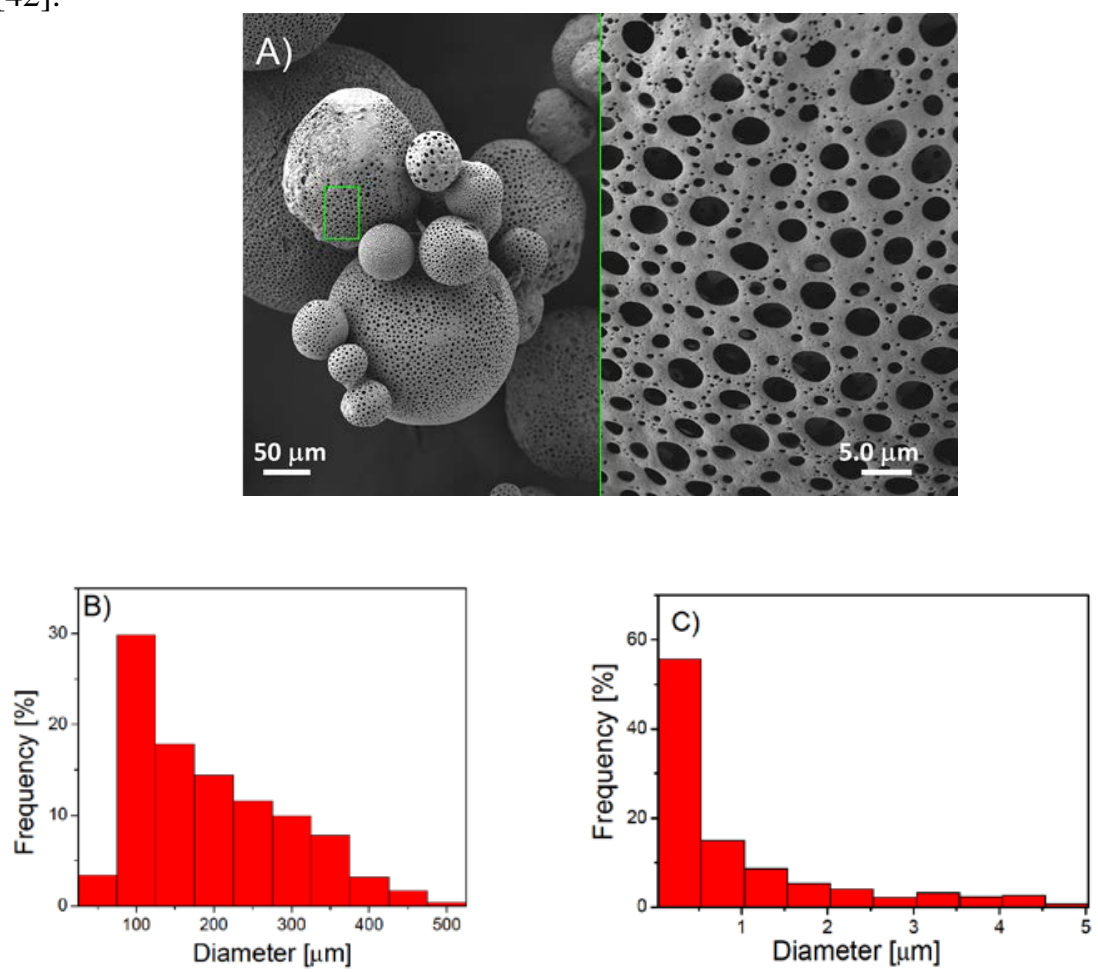

Figure 5. A) SEM images of PVA-PVAc-AMPS microspheres. B) Size distribution of PVA-PVAc-AMPS microspheres. C) Pore size distribution.

This result is related to the addition of organic solvents in the reaction medium during the polymerization stage. The removal of these solvents at the end of the reaction generates porosity in the final material $[13,42,43]$. An attempt was made to measure the BET surface area of the microspheres by performing a lyophilization pretreatment. This additional step was performed to avoid heating the samples during degassing, and possible damage to the polymeric microspheres. The result obtained was $0.2484 \pm 0.0042 \mathrm{~m}^{2} \mathrm{~g}^{-1}$. Despite being superior to those reported by Peixto et al. using standard BET equipment $[13,43]$, they are lower than expected according to 
SEM micrographs. Therefore, it was also not possible for us to obtain a conclusive result of the surface area of the PVA-PVAc-AMPS microspheres using this technique.

To estimate the average pore size, 800 pores were measured from SEM images, using the ImageJ program. A pore size distribution in the range of 0.03 and 4.82 microns was obtained with an average diameter of 0.93 microns (Figure 5C). Both the spherical morphology and the porosity in particles obtained are very important characteristics in medical applications [1-5,9-13]. Particularly, in embolization and chemoembolization procedures, the spherical morphology is an extremely important characteristic since it prevents the agglomeration of the particles responsible for the occlusion of the catheter with consequent interruption of the procedure [12,13]. For its part, porosity has a crucial role in the application of the material. As a point in favor, a high porosity provides a large specific area that can increase the adsorption capacity of the drug of interest, and modifies its release kinetics. But as a disadvantage it can affect its mechanical properties leading to failures during the chemoembolization procedure. To assess whether the porosity observed on the surface of the microspheres affects their mechanical behavior, the modulus of elasticity of the microspheres loaded with $\mathrm{MB}$ was measured. Figure 6 shows the typical Force versus displacement curve for one PVA-PVAc-AMPS microsphere loaded with MB. A highly linear relationship can be observed up to approximately 30\% deformation (dash).

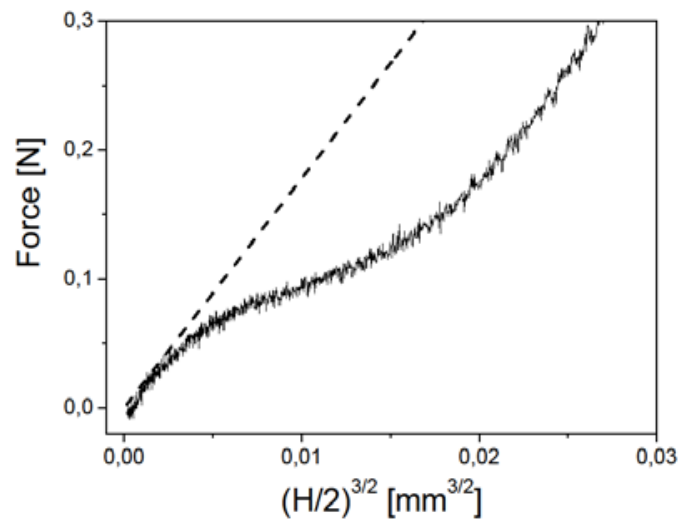

Figure 6. Typical Force versus $(\mathrm{H} / 2)^{3 / 2}$ curve for one PVA-PVAc-AMPS microsphere loaded with MB (line), and theoretical line (dash).

The correlation coefficient $\mathrm{R}^{2}$ for this microsphere was $>0.92$, and the other samples also presented high coefficients. These data therefore demonstrate the validity of Hertz's theory up to a deformation of 30\% for PVAPVAc-AMPS microspheres. The estimated average elastic modulus was $23.4 \pm 0.6 \mathrm{MPa}$, wich is in the range of the values estimated by Ashrafi et al. for microspheres (70-150 $\mu \mathrm{m}$ size range) loaded with drugs used in chemoembolization (Table 1) [44].

Table 1. Young's modulus of microspheres loaded with Doxorubicin (Dox), Irinotecan (Iri) and the MB loaded PVA-PVAc-AMPS microspheres from this work.

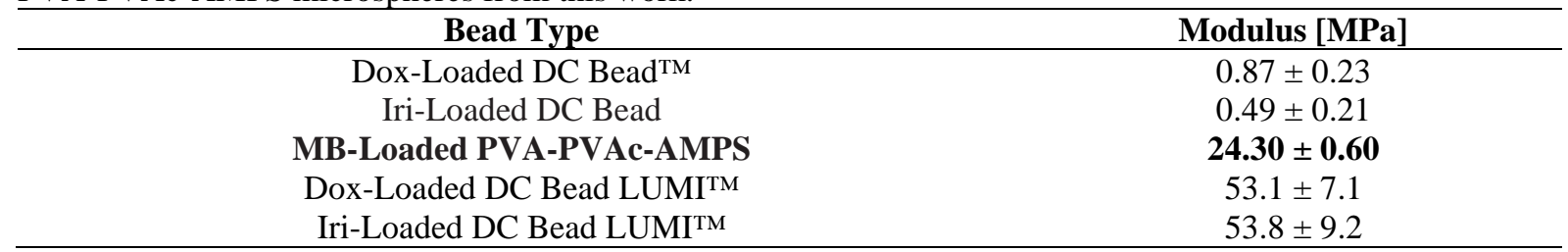

This preliminary result suggests that the porosity observed on the surface of the microspheres does not impair their elasticity, an important requirement for their use as chemoembolization agents. However, since the MB molecule has a simpler molecular structure than chemotherapeutic agents, each individual case must be investigated.

X-ray Diffraction (XRD) analyses were performed to identify the crystalline characteristics of the PVAc-AMPS and PVA-PVAc-AMPS spherical particles. Figure 7 shows the diffractograms obtained from samples before and after saponification (Figures 7A and 7B) and also from the commercial PVA (Figure 7C).

It can be seen that the PVAc-AMPS microspheres synthesized through free-radical suspension polymerization presented two very broad Bragg diffraction peaks in the region $2 \theta=10-30^{\circ}$ (Figure $7 \mathrm{~B}$ ), which can be related to the amorphous structure of the polymer matrix. In contrast, PVA commercial samples presented a completely different XRD diffractogram, which can be associated with a semi-crystalline polymer structure, emphasized by accentuated Bragg diffraction peaks at $2 \theta=19.38^{\circ}$ and $22.58^{\circ}$ (Figure $7 C$ ), values in agreement to PVA Bragg 
diffraction data reported in the literature [9,10]. PVA-PVAc-AMPS samples presented in general XRD diffractograms that were very similar to the ones observed for the PVAc-AMPS particles, confirming that the fraction of hydrolyzed acetate groups was low, and that the PVA is in the form of a thin outer layer [9,43]. This result was also corroborated by thermal analysis.

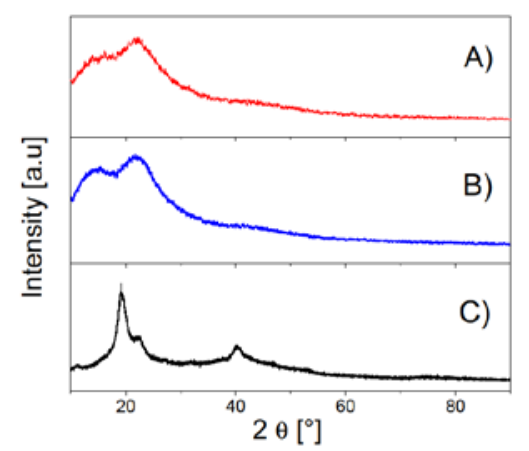

Figure 7. X-ray Diffraction of A) PVAc-AMPS microspheres, B) PVA-PVAc-AMPS microspheres and C) Commercial PVA.

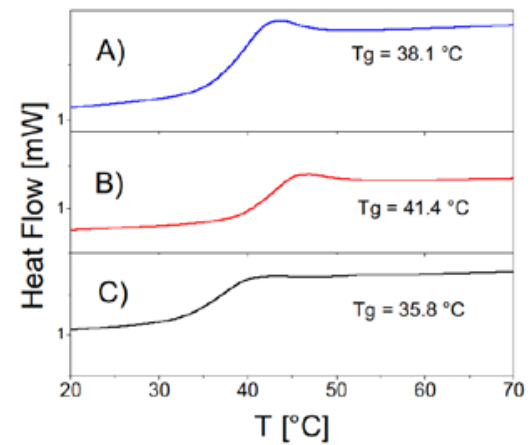

Figure 8. DSC curves of A) PVAc-AMPS microspheres. B) PVA-PVAc-AMPS microspheres. C) PVA-PVAc microspheres without AMPS.

Figure 8 shows the DSC curves of A) PVAc-AMPS microspheres, B) PVA-PVAc-AMPS microspheres and C) PVA-PVAc microspheres without AMPS. A $5.6^{\circ} \mathrm{C}$ increase in the Tg value is observed between B) and C), due to the incorporation of AMPS in the polymer chain during the copolymerization stage. In addition, $\mathrm{Tg}^{\prime} \mathrm{s}$ values of microspheres before and after the saponification are: $38.1{ }^{\circ} \mathrm{C}$ and $41.4^{\circ} \mathrm{C}$, respectively (Figures $8 \mathrm{~A}$ and $8 \mathrm{~B}$ ), indicating that the PVA shell constitutes a thin layer on the surface of the particles, as previously suggested, since pure PVA has a Tg value in the range about $75-85^{\circ} \mathrm{C}$ [12].

To estimate the degree of saponification of the PVA-PVAc-AMPS microspheres, the Fox equation was used:

$$
\frac{1}{T_{g}}=\sum \frac{\alpha_{i}}{T_{g, i}}
$$

where $T_{g}$ is the glass transition temperature of the PVA-PVAc-AMPS microspheres, and $T_{g, i}$ the theoretical glass transition temperature of each of the components of the copolymer [9], $\alpha_{i}$ is the mass fraction of component $\mathrm{i}$ in the copolymer particles.

The results obtained indicated that the PVA shell is $8.5 \mathrm{wt} \%$ of the PVA-PVAc-AMPS microspheres. Similar results have been reported by other authors, where the PVA shell constitutes a very thin layer at the surface of the particles $[9,13]$. Oliveira et al. have reported that a thin layer of PVA appears to be sufficient to guarantee the biocompatibility of the particles, and that for embolization and chemoembolization procedures, a considerable amount of PVAc in the nucleus of the microspheres ensures that the particle deforms within of the blood vessel and adjust to its shape to promote more efficient physical occlusion of the blood vessel [9,12]. However, if it is of interest to increase the PVA content of the final polymeric particle, some parameters of the saponification process should be modified, such as longer reaction times and higher alkali concentrations $[9,10,45,46]$.

\subsection{Adsorption of MB onto sulfonated PVA microspheres}




\subsubsection{Effect of $\mathrm{pH}$ on $\mathrm{MB}$ adsorption}

$\mathrm{pH}$ is an important parameter that controls the adsorption processes. In this work the adsorption capacity of MB on sulfonated microspheres was studied as a function of $\mathrm{pH}$ at ambient temperature, with $100 \mathrm{mg} \mathrm{L}^{-1}$ as initial dye concentration. Figure 9A shows the amount of MB adsorbed by the PVA-PVAc-AMPS microspheres at different $\mathrm{pH}$ values, after six hours stirring.
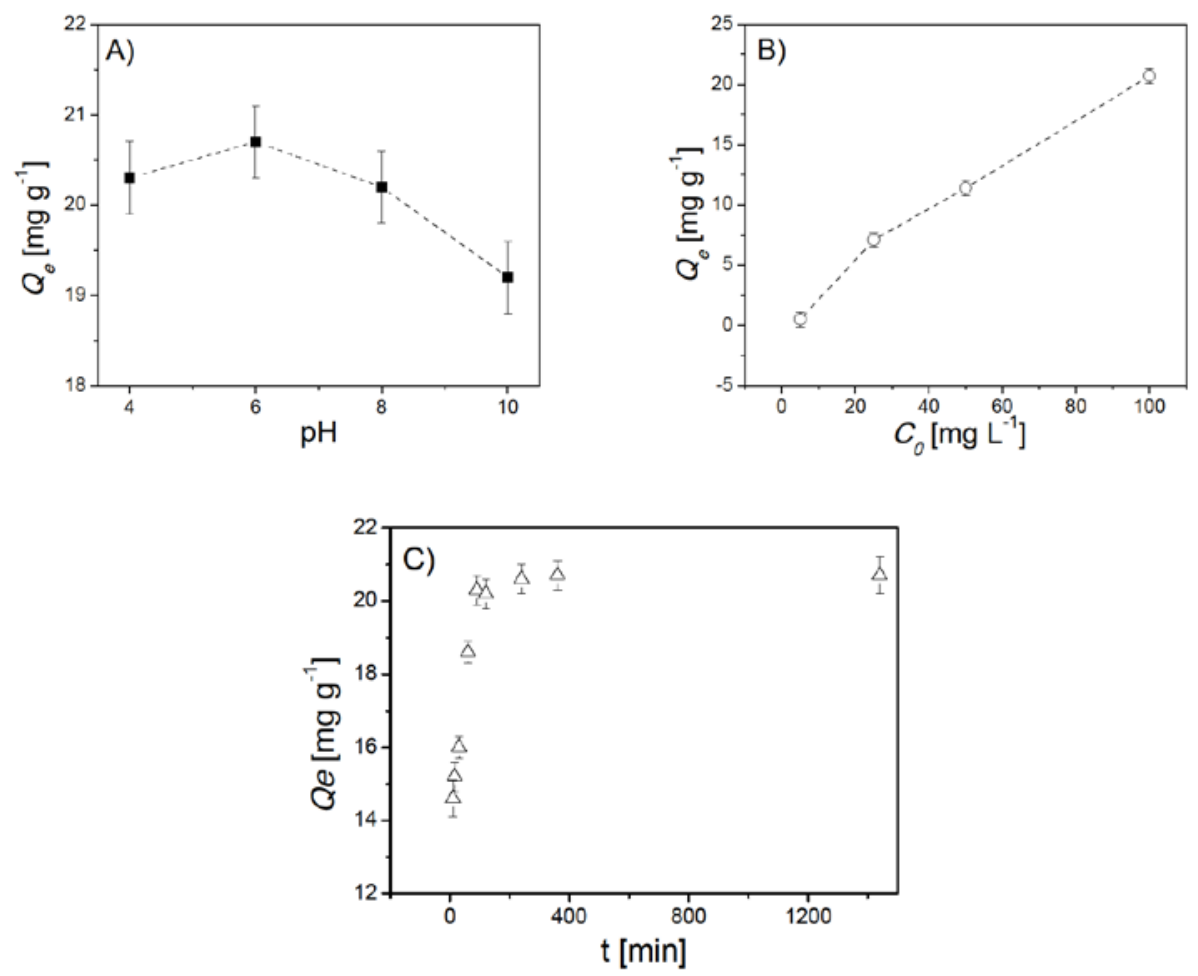

Figure 9. MB adsorption on sulfonated PVA microspheres. A) Effect of pH. B) Effect of concentration. C) Effect of contact time.

It can be seen that the adsorption capacity increases when the $\mathrm{pH}$ values of the solution increase from 4 to 6 , reaching a maximum value of $20.7 \mathrm{mg} \mathrm{g}^{-1}$ at $\mathrm{pH}=6$. At $\mathrm{pH}>6$ values, the adsorption capacity decreases with the $\mathrm{pH}$ increase. This behavior is associated mainly with the $-\mathrm{N}\left(\mathrm{CH}_{3}\right)_{2}$ groups present in $\mathrm{MB}$ and $-\mathrm{SO}_{3}^{-}$in $\mathrm{PVA}^{-}$ PVAc-AMPS, which are strongly influenced by the $\mathrm{pH}$ of the solution.

At the $4 \leq \mathrm{pH} \leq 10$ range studied, $\mathrm{MB}(\mathrm{pKa}=3.8)$ is dissolved as an ionic dye:

$$
M B-C l \rightarrow M B^{+}+C l^{-}
$$

On the other hand, when the $\mathrm{pH}$ value increases from 4 to 6 the microspheres contain negatively charged $-\mathrm{SO}_{3}^{-}$groups, and the adsorption process occurs because of the electrostatic attractions between these counter ions:

$$
\mathrm{R}-\mathrm{SO}_{3}^{-}+M B^{+} \rightarrow R-\mathrm{SO}_{3} \mathrm{MB}
$$

In addition, other mechanism for MB adsorption is possible. A chemical reaction between -OH group of PVA surface, and the reactive group $\mathrm{Cl}^{-}$may occur, resulting in $\mathrm{MB}^{+}$adsorption on the surface and eliminating $\mathrm{HCl}$ in solution $[47,48]$.

Under acidic $\mathrm{pH}$ conditions $(\mathrm{pH}<6)$, the excess of $\mathrm{H}^{+}$competes with the $\mathrm{MB}^{+}$cations for the active sites of adsorption. The most of sulfonic groups $-\mathrm{SO}_{3}^{-}$are protonated, forming $-\mathrm{SO}_{3} \mathrm{H}$ [46], in addition the -OH groups of PVA are also protoned, as consequence, the latter groups exhibit a coulombic repulsion with $\mathrm{MB}^{+}$groups:

$$
-\mathrm{OH}+\mathrm{H}^{+} \rightarrow \mathrm{OH}_{2}^{+}+\mathrm{MB}^{+} \quad \ldots \text { (coulombic repulsion) [48] }
$$

Both reasons tend to decrease the adsorption capacity at low $\mathrm{pH}$. On the other hand, at $\mathrm{pH}>6$, a drop in adsorption capacity was observed. The motive of the adsorption loss at the highly basic solutions is "charge screening effect” of excess $\mathrm{Na}^{+}$(from $\mathrm{NaOH}$ solution) in the adsorption media, which shields the anionic functional groups and prevents effective negative-positive interactions of adsorbent and adsorbate [49]. 


\subsubsection{Effect of initial MB concentration on dye adsorption capacity}

Different concentrations of $\mathrm{MB}\left(5,25,50\right.$ and $\left.100 \mathrm{mg} \mathrm{L}^{-1}\right)$, at $\mathrm{pH}$ 6, were used to study the effect of the initial dye concentration on the adsorption capacity of PVA-PVAc-AMPS microspheres. As seen in Figure 9B, the dye adsorption capacity of microspheres increases with increasing concentration of MB reaching a $Q_{e}$ of $20.7 \mathrm{mg} \mathrm{g}^{-1}$ after six hours. The increase in adsorption capacity with the increase in initial dye concentration has also been observed by other authors in polymer hydrogels, and can be attributed to the greater availability of dye molecules in the vicinity of the polymer [49], and to the high driving force for mass transfer [48,50].

\subsubsection{Effect of contact time on dye adsorption capacity}

Figure 9C shows the effect of the contact time on MB adsorption $\left(100 \mathrm{mg} \mathrm{L}^{-1}, \mathrm{pH}=6\right)$. It is observed that the dye adsorption capacity in the PVA-PVAc-AMPS microspheres increases rapidly within the first 15 minutes. In the subsequent process, the adsorption gradually reaches equilibrium with an adsorption capacity of $20.7 \mathrm{mg} \mathrm{g}^{-1}$ at six hours of contact with the MB solution. The rapid uptake of MB at first minutes may indicate that most of the active sites of the samples are exposed for interaction with the dye [51,52].

\subsubsection{Adsorption kinetics}

The adsorption kinetics describes how fast the adsorption occurs and also gives information on the factors affecting the rate of reaction. To investigate the mechanism and rate-controlling step, three kinetic models, such as the pseudo-first-order, the pseudo-second-order and the intra-particle diffusion, were used to evaluate the experimental data.

The pseudo-first-order kinetics model assumes that the adsorption is originated from a physical process [4752]. It is given as:

$$
\log \left(Q_{e}-Q_{t}\right)=\log Q_{e}-\frac{K_{1}}{2.303} t
$$

Where $Q_{t}$ and $Q_{e}$ [mg g-1] indicate the amount of the dye adsorbed at time $t$ and at equilibrium, respectively; $K_{1}$ is the pseudo-first-order rate constant $\left[\mathrm{min}^{-1}\right.$ ] for the adsorption process. The values of $Q_{e}$ and $K_{1}$ can be obtained from the intercept and slope values of the linear plot of $\log \left(Q_{e}-Q_{t}\right)$ against $t$.

The pseudo-second-order kinetics model can predict the behavior over the whole adsorption process and is in agreement with the chemisorption mechanism being the rate-controlling step [47-52]. It can be represented with the following equation:

$$
\frac{t}{Q_{t}}=\frac{1}{K_{2} Q_{e}^{2}}+\frac{1}{Q_{e}} t
$$

Where $K_{2}$ [g mg $\mathrm{gmin}^{-1}$ ] is the rate constant of the pseudo-second-order model. The values of $K_{2}$ and $Q_{e}$ can be obtained from the plot of $\frac{t}{Q t}$ against $t$.

The regression plots of Lagergren-first-order kinetic model and pseudo-second-order kinetic model are shown in Figures 10A and 10B, respectively. The corresponding kinetic parameters for the two kinetic models are listed in Table 2. The results obtained show that the pseudo second order model agrees better with the experimental data than the pseudo first order model.

As seen in Table 2, the calculated values of the adsorption capacity (20.8 $\left.\mathrm{mg} \mathrm{g}^{-1}\right)$ using the pseudo-second order model are closer to the experimental values $\left(20.7 \mathrm{mg} \mathrm{g}^{-1}\right)$, while the values calculated from the pseudo first order model differ widely from the experimental data. In addition, the values of correlation coefficients $\mathrm{R}^{2}$ of the pseudo second order model in PVA-PVAc-AMPS microspheres are much closer to unit than those of the pseudo first order model (0.99997 and 0.89109, respectively). These results suggest that the adsorption process to follow a pseudo-second order kinetic model, and that a chemical reaction might be responsible for adsorption of MB onto PVA-PVAc-AMPS microspheres. Other authors have also reported that the adsorption kinetics of many dye species in various materials conforms to the pseudo-second order kinetic model [48].

To describe intra-particle diffusion in porous materials, Weber's model is one of the most used methods $[47,49,51]$. It can be expressed as:

$$
Q_{t}=K_{p} \mathrm{t}^{0.5}+C
$$

Where $Q_{t}\left[\mathrm{mg} \mathrm{g}^{-1}\right]$ indicates the amount of the adsorbed dye at time $t ; K_{p}\left[\mathrm{mmol} \mathrm{g}^{-1} \mathrm{~h}^{-0.5}\right]$ is the intra-particle diffusion rate constant and $\mathrm{C}$ is the intercept which gives information about the thickness of the boundary layer [47]. When the intra-particle diffusion model is the only rate-controlling step, the plot of $Q_{t}$ against $\mathrm{t}^{0.5}$ gives a line that passes through the origin, if not, the boundary layer diffusion affects the adsorption to some extent, but also other kinetic models may control the rate of adsorption, all of which may be operating simultaneously [47]. 

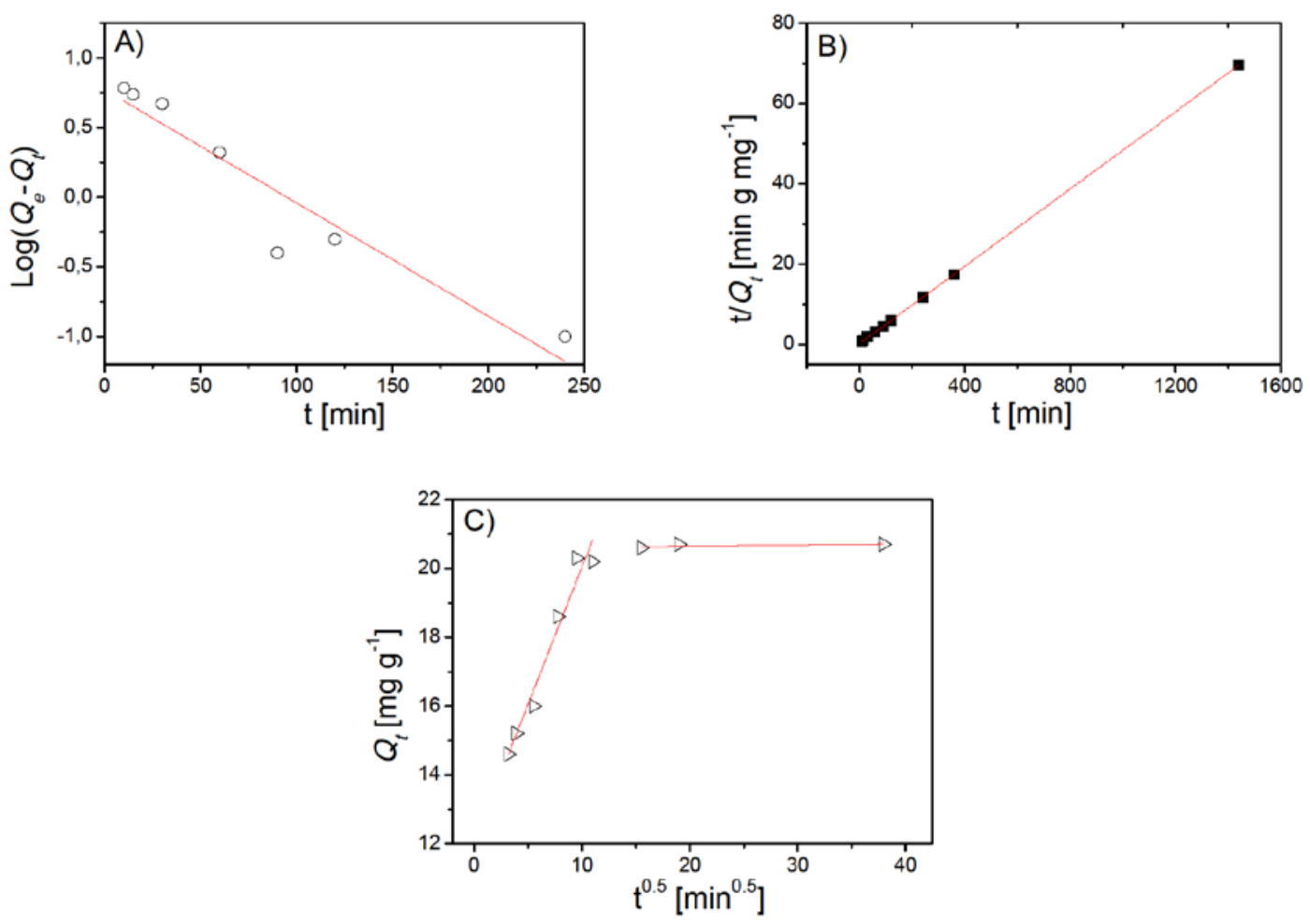

Figure 10. A) Pseudo-first-order. B) Pseudo-second-order and C) Intra-particle diffusion kinetics models plots for MB adsorption onto sulfonated PVA microspheres.

Table 2. Kinetic parameters for the MB adsorption onto PVA-PVAc-AMPS microspheres.

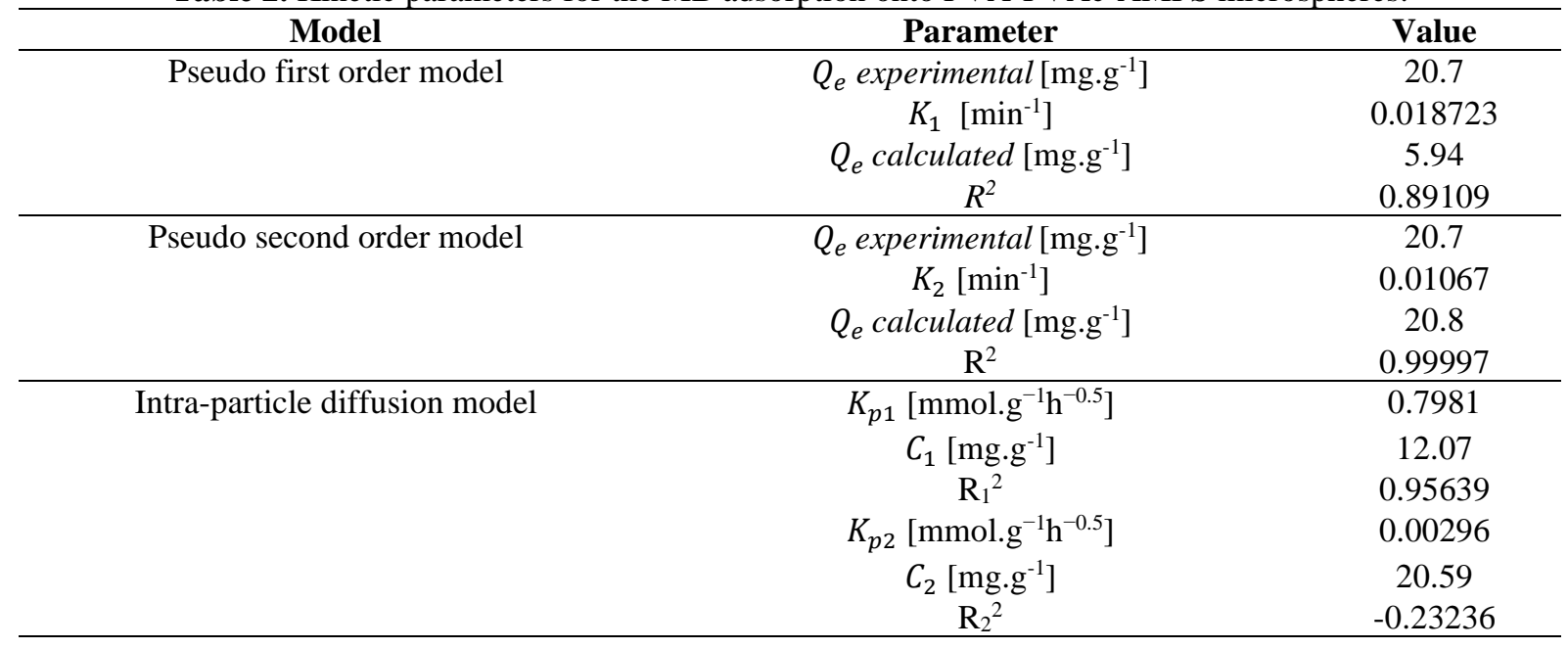

Figure 10C shows intra-particle diffusion kinetics for adsorption of MB on PVA-PVAc-AMPS microspheres. It can be observed that the adsorption plots of $Q_{t}$ versus $t^{0.5}$ are not linear over the whole time range, and that it does not pass through the origin. This means that the intra-particle diffusion model is not the step that controls the rate of adsorption, and that other adsorption mechanisms are also involved in the process [47,53]. As seen in Figure 10C, two zones with different slopes can be distinguished in the adsorption curve. The first portion can be assigned to the film diffusion, that is, the diffusion of MB molecules from solution towards the external surface of the polymer, where the adsorption rate is very high. The second portion corresponds to intra-particle diffusion of dye molecules through pores of the microspheres, where intra-particle diffusion is rate-controlling [47,51,53,54].

The parameters $K_{p}$ and $\mathrm{R}^{2}$ of all three linear segments of $Q_{t}$ versus $t^{0.5}$ are shown in Table 2 . In accordance with results reported by other authors for the adsorption of $\mathrm{MB}$, it can be seen that the $K_{p}$ values increase as $K_{p 1}>K_{p 2}$; indicating that the diffusion of the film is a rapid process, while the intraparticle diffusion is a gradual process $[47,53]$. 


\subsection{In vitro release of MB loaded in PVA-PVAc-AMPS microspheres}

The study of MB desorption was performed in SBF solution at $37^{\circ} \mathrm{C}$ to simulate in vivo release, by competitive ion-exchange displacement.

Figure 11 shows a release profile of MB from PVA-PVAc-AMPS microspheres. An initial burst release within the first hour can be observed, in which the unbound MB is rapidly released from the beads, followed by a slower, more controlled release of bound $\mathrm{MB}$ as it is displaced by ions in the elution medium, reaching $8.6 \%$ release after four hours.

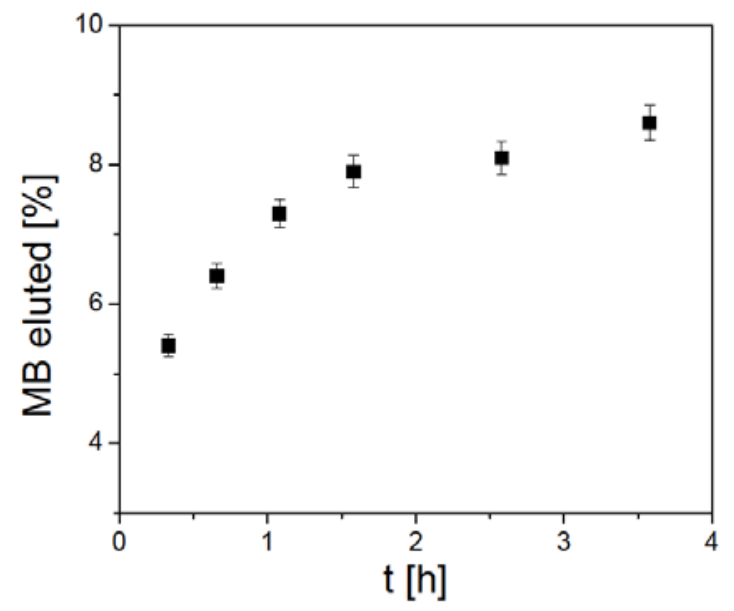

Figure 11. Release profiles of MB into SBF from PVA-PVAc-AMPS microspheres at $37^{\circ} \mathrm{C}$.

To study the mechanism of desorption the Ritger-Peppas equation was used:

$$
\frac{M_{t}}{M_{\infty}}=K t^{n}
$$

Where $M_{t}$ is the fraction of the adsorbed dye that was released at time $t$ and $M_{\infty}$ is the fraction of the adsorbed dye that was released at equilibrium. $K$ is the release velocity constant that incorporates the geometrical characteristic of the system and $n$ is a feature desorption parameter indicating the type of dye desorption mechanism [55,56]. This equation is applicable for the first $60 \%$ of fractional release, and according to this model, in the case of spherical samples, $\mathrm{n}$ approaches to 0.43 for Fickian diffusion release mechanism (dye diffusion is dominant), $0.43<n<0.85$ for non-Fickian release (anomalous), this means that drug release followed both diffusion and matrices erosion controlled mechanisms. If $\mathrm{n}$ is more than 1 desorption mechanism follow case II transport (Table 3) [55].

Table 3. Ritger-Peppas diffusional exponent value ranges and associated diffusional release mechanisms of controlled release systems taken from literature.

\begin{tabular}{cccc}
\hline & Diffusional expontent, $\boldsymbol{n}$ & & Drug release mechanism \\
\hline Thin film & Cylindrical sample & Spherical sample & \\
\hline 0.5 & 0.45 & 0.43 & Fickian diffusion \\
$0.5<n<1.0$ & $0.45<n<0.89$ & $0.43<n<0.85$ & Anomalous (non-Fickian) transport \\
1.0 & 0.89 & 0.85 & Case-II transport \\
\hline
\end{tabular}

Data obtained from in vitro MB release studies were plotted as logarithm of the fraction of dye released versus logarithm of time:

$$
\log \left(\frac{M_{t}}{M_{\infty}}\right)=\log K+n \log (t)
$$

Parameters $n$ and $K$ were calculated from the slope and the intercept of equation (10), (not shown here). The values obtained were 0.26 and $0.255 \mathrm{~min}^{-1}$, respectively. This result suggests that the dye release from the PVAPVAc-AMPS microspheres under simulated physiological conditions is controlled by a diffusion process (Table 3). 


\section{Conclusions}

Novel PVA-PVAc-AMPS microspheres have been synthesized using free radical copolymerization of VAc and AMPS in stages, followed by saponification. The porous sulfonated microspheres were obtained with good sphericity and an average diameter of 171 microns and good elasticity modulus. The PVA layer is estimated to conform about an $8.5 \%$ of the microspheres volume, with a polyvinyl acetate inner core. The adsorption/release capacity of positively charged molecules was demonstrated using MB as a model drug. Maximum adsorption capacity was found at $\mathrm{pH}=6,100 \mathrm{mg} \mathrm{L}-1 \mathrm{MB}$ concentration, 2 hours adsorption time at room temperature. The adsorption kinetic studies revealed that the data were well described by the pseudo-second-order kinetic model, indicating that the MB adsorption mechanism is controlled by a chemisorption process. The release data fitted to the Ritger-Peppas equation, indicating a MB release mechanism controlled by Fickian diffusion under simulated physiological conditions.

\section{Acknowledgments}

The authors wish to thank the National Atomic Energy Commission (CNEA) for their financial support, to the Division Isotopic Separation Pilcaniyeu Technologilcal Complex and the Materials Physicochemistry Department of the Bariloche Atomic Center for the provision of equipment for the physical characterization of the samples, and Messrs. Fernando Becker and Bernardo Pentke for their technical assistance.

\section{References}

[1] Biondi M, Fusco S, Lewis AL, Netti PA. New insights into the mechanisms of the interactions between Doxorubicin and the ion-exchange hydrogel DC Bead ${ }^{\mathrm{TM}}$ for use in transarterial chemoembolization (TACE). Journal of Biomaterials Science. Polymer Edition. 2012;23(1-4):333-354. https://doi.org/10.1163/ $092050610 \times 551934$

[2] Anand V, Kandarapu R, Garg S. Ion-exchange resins: carrying drug delivery forward. Drug Discovery Today. 2001;6(17):905-914. https://doi.org/10.1016/S1359-6446(01)01922-5.

[3] Chen YAN, Burton MA, Codde JP, Napoli S, Martins IJ, Gray BN. Evaluation of ion-exchange microspheres as carriers for the anticancer drug Doxorubicin: in-vitro studies. Journal of Pharmacy and Pharmacology. 1992;44(3):211-215. https://doi.org/10.1111/j.2042-7158.1992.tb03583.x

[4] Liu Z, Cheung R, Wu XY, Ballinger JR, Bendayan R, Rauth AM. A study of doxorubicin loading onto and release from sulfopropyl dextran ion-exchange microspheres. Journal of Control Release. 2001;77(3):213224. https://doi.org/10.1016/S0168-3659(01)00473-4

[5] Liu Z, Wu XY, Bendayan R. In vitro investigation of ionic polysaccharide microspheres for simultaneous delivery of chemosensitizer and antineoplastic agent to multidrug resistant cells. Journal of Pharmaceutical Science. 1999;88(4):412-418. https://doi.org/10.1021/js9803353

[6] Srikanth MV, Sunil SA, Raol NS, Uhumwangho MU, Ramana Murthy KV. Ion exchange resins as controlled drug delivery carriers. Journal of Scientific Research. 2010; 2(3): 597-611. https://doi.org/10.3329/ jsr.v2i3.4991

[7] Anand V, Kandarapu R, Garg S, Ion-exchange resins: carrying drug delivery forward. Drug Discovery Today. 2001;6(17):905-914. https://doi.org/10.1016/S1359-6446(01)01922-5.

[8] Heaysman CL, Phillips GJ, Lloyd AW, Lewis AL. Synthesis and characterization of cationic quaternary ammonium modified polyvinyl alcohol hydrogel beads as a drug delivery embolisation system. Journal of Materials Science. Materials in Medicine. 2016;27:53(10 pp). https://doi.org/10.1007/s10856-015-5637-6

[9] Oliveira M, Matos Cirilo LC, Nele M, Pinto JC. Synthesis of spherical core shell poly(vinyl acetate)/poly(vinyl alcohol) particles for use in vascular embolization: study of morphological and molecular modifications during shell formation, Polymer Engineering and Science. 2015;55(10):2237-2244. https://doi.org/10.1002/pen.24109

[10] Semenzim VL, Basso GG, da Silva DA, de Vasconcellos A, Agreli G, Marques Lima Oliveira AP. Synthesis and characterization of novel, highly crystalline poly(vinyl alcohol) microspheres for chemoembolization therapy. Journal of Applied Polymer Science. 2011;121(3):1417-1423. https://doi.org/10.1002/app.33623.

[11] Lee SG, Lyoo WS. Preparation of monodisperse poly(vinyl alcohol) microspheres by heterogeneous surface saponification and iodine complex formation. Journal of Applied Polymer Science. 2008;107(3):1701-1709. https://doi.org/10.1002/app.27194

[12] Peixoto LS, Silva FM, Niemeyer MAL, Espinosa G, Melo PA, Nele M, Pinto JC. Synthesis of poly(vinyl alcohol) and/or poly(vinyl acetate) particles with spherical morphology and core-shell structure and its use in vascular embolization. Macromolecular Symposia. 2006;243(1):190-199. https://doi.org/10.1002/masy. 200651118 
[13] Peixoto LS, Melo PA, Nele M, Pinto JC. Expanded core/shell poly(vinyl acetate)/poly(vinyl alcohol) particles for embolization. Macromolecular Materials and Engineering. 2009;294(8):463-471. https://doi.org/10.1002/ mame.200900028

[14] Malagari K, Iezzi R, Goldberg SN, Bilbao JI, Sami A, Akhan O, Giuliante F, Pompili M, Crocetti L, V. Valentini, Gasbarrini A, Colosimo C, Manfredi R. The ten commandments of chemoembolization: expert discussion and report from Mediterranean Interventional Oncology (MIOLive) congress 2017. European Review for Medical and Pharmacological Sciences. 2018;22(2):372-381. doi: 10.26355/eurrev_201801 14184

[15] Negussie AH, Dreher MR, Gacchina Johnson C, Tang Y, Lewis AL, Storm G, Sharma KV, Wood BJ. Synthesis and characterization of image-able polyvinyl alcohol microspheres for image-guided chemoembolization. Journal of Materials Science. Materials in Medicine. 2015;26(6):198. https://doi.org/10.1007/s10856-015-5530-3

[16] Lewis AL, Gonzalez MV, Leppard WS, Brown JE, Stratford PW, Phillips GJ, Lloyd AW. Doxorubicin eluting beads-1: Effects of drug loading on bead characteristics and drug distribution. Journal of Materials Science. Materials in Medicine. 2007;18(9):1691-1699. https://doi.org/10.1007/s10856-007-3068-8

[17] Lewis AL, Dreher MR, O’Byrne V, Grey D, Caine M, Dunn A, et al. DC BeadM1TM: towards an optimal transcatheter hepatic tumour therapy. Journal of Materials Science. Materials in Medicine. 2016;27:13(12 pp). https://doi.org/10.1007/s10856-015-5629-6

[18] Malagari K, Chatzimichael K, Alexopoulou E, Kelekis A, Hall B, Dourakis S, Delis S, Gouliamos A, Kelekis D. Transarterial chemoembolization of unresectable hepatocellular carcinoma with drug eluting beads: results of an open-label study of 62 patients. Cardiovascular and Interventional Radiology. 2008; 31(2): 269-280.

[19] Duran R, Sharma K, Dreher MR, Ashrafi K, Mirpour S, De Lin M, et al. A novel inherently radiopaque bead for transarterial embolization to treat liver cancer-A pre-clinical study. Theranostics. 2016;6(1):28-39. https://doi.org/10.1007/s00270-007-9226-z

[20] Ashrafi K, Tanga Y, Brittona H, Domenge O, Blino D, Bushby AJ, Shuturminska K, et al. Characterization of a novel intrinsically radiopaque Drug-eluting bead for image guided therapy: DC Bead LUMI ${ }^{\mathrm{TM}}$. Journal of Control Release. 2017;250:36-47. https://doi.org/10.1016/j.jconrel.2017.02.001

[21] Yefimova SL, Bespalova II, Grygorova GV, Sorokin AV, Mateychenko PV, Cui XQ, Malyukin YV. Synthesis and characterization of mesoporous CaCO3@PSS microspheres as a depot system for sustained Methylene Blue delivering. Microporous and Mesoporous Materials. 2016;236:120-128. https://doi.org/ 10.1016/j.micromeso.2016.08.037

[22] Tardivo JP, Del Giglio A, de Oliveira CS, Gabrielli DS, Junqueira HC, Tada DB. Methylene blue in photodynamic therapy: From basic mechanisms to clinical applications. Photodiagnosis and Photodynamic Therapy. 2005;2(3):175-191. https://doi.org/10.1016/S1572-1000(05)00097-9

[23] Oz M, Lorke DE, Petroianu GA. Methylene blue and Alzheimer's disease. Biochemical Pharmacology. 2009;78(8):927-932. https://doi.org/10.1016/j.bcp.2009.04.034.

[24] Kokubo T, Takadama H. How useful is SBF in predicting in vivo bone bioactivity. Biomaterials. 2006; 27(15):2907-2915. https://doi.org/10.1016/j.biomaterials.2006.01.017.

[25]Arai K, Ogiwara Y. Copolymerization of sodium 2-acrylamido-2 methylpropanesulfonate with vinyl acetate. Die Makromoleculare Chemie. Rapid Communications. 1981;2:363-367. https://doi.org/10.1002/marc. 1981.030020510

[26] Moritani T, Yamauchi J. Functional modification of poly(vinyl alcohol) by copolymerization: II. Modification with a sulfonate monomer. Polymer. 1998;39(3):553-557. https://doi.org/10.1016/S00323861(97)00262-0

[27] Moritani T, Kajitani K. Functional modification of poly(vinyl alcohol) by copolymerization: 1. Modification with carboxylic monomers. Polymer. 1997;38(12):2933-2945. https://doi.org/10.1016/S0032-3861(96) 00825-7

[28] Vicari R. Vinyl alcohol copolymers for use in aqueous dispersions and melt extruded articles. US Patent 8,466.243 B2, 2013.

[29] Young C, Rozario K, Serra C, Poole-Warren L, Martens P. Poly(vinyl alcohol)-heparin biosynthetic microspheres produced by microfluidics and ultraviolet photopolymerisation. Biomicrofluidics. 2013;7(4):044109. https://doi.org/10.1063/1.4816714

[30] Yang SB, Yoo SH, Lee JS, Kim JW, Yeum JH. Surface properties of a novel poly(vinyl alcohol) film prepared by heterogeneous saponification of poly(vinyl acetate) film. Polymers. 2017;9:493(9 pp). https://doi.org/ 10.3390/polym9100493

[31] Zhao X, Qiu Z, Zhang Y, Zhong H, Huang W, Tang Z. Zwitterionic polymer p(AM-DMC-AMPS) as a low molecular weight encapsulator in deep water drilling fluid. Applied Sciences. 2017;7:594(12 pp). https://doi.org/10.3390/app7060594. 
[32] Xin H, Ao D, Wang X, Zhu Y, Zhang J, Tan Y. Synthesis, characterization, and properties of copolymers of acrylamide with sodium 2-acrylamido-2-methylpropane sulfonate with nano silica structure. Colloid and Polymer Science. 2015;293:1307-1316. https://doi.org/10.1007/s00396-015-3512-0

[33] Bergamasco J. Synthesis and characterization of poly (vinyl alcohol) microspheres and their use as supports for immobilizing lipase produced by Rhizomucor miehei and its catalytic study in the transesterification reaction of soybean oil for the production of biodiesel via ethyl route. [Master Thesis]. Paulista State University Julio de Mesquita Filho, Instituto of Biosciences, Letters and Exact Sciences. São José do Rio Preto. 2013. (in Portuguese). http://hdl.handle.net/11449/94804

[34] Dibbern Brunelli D, Atvars TDZ, Joekes I, Barbosa VC. Mapping phases of poly(vinyl alcohol) and poly(vinyl acetate) blends by FTIR microspectroscopy and optical fluorescence microscopy. Journal of Applied Polymer Science. 1998;69(4):645-655. https://doi.org/10.1002/(SICI)1097-4628(19980725)69:4 $<645:$ :AID-APP3>3.0.CO;2-J

[35] Renuka Devi KB, Madivanane R. Normal coordinate analysis of polyvinyl acetate. IRACST-Engineering Science and Technology: An International Journal (ESTIJ). 2012;2(4):795-799.

[36] Mansur HS, Sadahira CM, Souza AN, Mansur AAP. FTIR spectroscopy characterization of poly(vinyl alcohol) hydrogel with different hydrolysis degree and chemically crosslinked with glutaraldehyde. Materials Science and Engineering C. 2008;28(4):539-548. https://doi.org/10.1016/j.msec.2007.10.088

[37] Socrates G. Infrared and Raman characteristic group frequencies. Tables and charts, third ed., Chichester, New York: Wiley; 2001.

[38] Quiao J, Hamaya T, Okada T. Chemically modified poly(vinyl alcohol)-poly(2-acrylamido-2-methyl-1propanesulfonic acid) as a novel proton-conducting fuel cell membrane. Chemistry of Materials. 2005;17(9):2413-2421. https://doi.org/10.1021/cm048260t

[39] Erdemi H, Bozkurt A, Meyer WH. PAMPSA-IM based proton conducting polymer electrolytes. Synthetic Metals. 2004;143(1):133-138. https://doi.org/10.1016/j.synthmet.2003.10.022

[40] Shoueir KR, Atta AM, Sarhan AA, Akl MA. Synthesis of monodisperse core shellPVA@P(AMPS-coNIPAm) nanogels structured for pre-concentration of Fe(III) ions. Environmental Technology. 2016;38(8):967-978. https://doi.org/10.1080/09593330.2016.1215351

[41] Hicyilmaza AS, Seckinb AK, Cerkeza I. Synthesis, characterization and chlorination of 2-acrylamido-2methylpropane sulfonic acid sodium salt-based antibacterial hydrogels. Reactive and Functional Polymers. 2017;115:109-116. https://doi.org/10.1016/j.reactfunctpolym.2017.04.014

[42] Ambrosio L, Verón MG, Silin N, Prado M. Synthesis and characterization of fluorescent PVA/PVAcrodhamine microspheres. Materials Research. 2019;22(4):e20190133. https://doi.org/10.1590/1980-5373mr-2019-0133

[43] Peixoto LS. Production of spherical PVA / PVAc particles with shell-core morphology for use in vascular embolization. [Master Thesis]. Federal University of Rio de Janeiro COPPE, Rio de Janeiro. 2007. (in Portuguese).

[44] Ashrafi K, Tang Y, Britton H, Domenge O, Blino D. Characterization of a novel intrinsically radiopaque drug-eluting bead for image-guided therapy: DC Bead LUMI ${ }^{\mathrm{TM}}$. Journal of Controled Release. 2017;250:3647. https://doi.org/10.1016/j.jconrel.2017.02.001

[45] Kim CJ, Lee P. Composite poly(vinyl alcohol) beads for controlled drug delivery. Pharmaceutical Research. 1992;9(1):10-16. https://doi.org/10.1023/A:1018963223484

[46] Jung HM, Lee EM, Ji BC, Deng Y, Yun JD, Yeum JH. Poly(vinyl acetate)/poly(vinyl alcohol)/montmorillonite nanocomposite microspheres prepared by suspension polymerization and saponification. Colloid and Polymer Science. 2007;285(6):705-710. https://doi.org/10.1007/s00396-0061623-3

[47] Yu J, Li Y, Lu Q, Zheng J, Yang S, Jin F, Wang Q, Yang W. Synthesis, characterization and adsorption of cationic dyes by $\mathrm{CS} / \mathrm{P}(\mathrm{AMPS}-\mathrm{co}-\mathrm{AM})$ hydrogel initiated by glow-discharge-electrolysis plasma. Iranian Polymer Journal. 2016;25(5):423-435. https://doi.org/10.1007/s13726-016-0434-8

[48] Umoren SA, Etim UJ, Israel AU. Adsorption of methylene blue from industrial effluent using poly (vinyl alcohol). Journal of Materials and Environmental Science. 2013;4(1):75-86.

[49] Hosseinzadeh H, Khoshnood N. Removal of cationic dyes by poly(AA-co-AMPS)/montmorillonite nanocomposite hydrogel. Desalination and Water Treatment. 2015;57(14):6372-6383. https://doi.org/ 10.1080/19443994.2015.1008052

[50] Bulut Y, Aydin H. A kinetics and thermodynamics study of methylene blue adsorption on wheat shells. Desalination. 2006;194(1-3):259-267. https://doi.org/10.1016/j.desal.2005.10.032

[51] Shoueir KR, Sarhan AA, Atta AM, Akl MA. Macrogel and nanogel networks based on crosslinked poly(vinyl alcohol) for adsorption of methylene blue from aqua system. Environmental Nanotechnology. Monitoring and Management. 2016;5:62-73. https://doi.org/10.1016/j.enmm.2016.03.001 
[52] El Hag Ali A. Removal of heavy metals from model wastewater by using Carboxymehyl Cellulose/2Acrylamido-2-methyl propane sulfonic acid hydrogels. Journal of Applied Polymer Science. 2012;123(2):763-769. https://doi.org/10.1002/app.34470

[53] Chen Z, Zhang J, Fua J, Wang M, Wang X, Han R, Xu Q. Adsorption of methylene blue onto poly(cyclotriphosphazene-co-4,4'-sulfonyldiphenol) nanotubes: Kinetics, isotherm and thermodynamics analysis. Journal of Hazardous Materials. 2014;273:263-271. https://doi.org/10.1016/j.jhazmat.2014.03.053

[54] Suteu D, Zaharia C, Rusu G. Kinetic study of methylene blue dye sorption from liquid media onto lignin. In: International Cientific Conference, Unitech’10. Gabrovo, Bulgaria. November 19 - 20, 2010; volume III:253528.

[55] Ritger PL, Peppas NA. A simple equation for description of solute release II. Fickian and anomalous release from swellable devices. Journal of Controled Release. 1987;5(1):37-42. https://doi.org/10.1016/01683659(87)90035-6

[56] Chime SA, Onunkwo GC, Onyishi II. Kinetics and mechanisms of drug release from swellable and non swellable matrices: A review. Research Journal of Pharmaceutical, Biological and Chemical Science. 2013;4(2):97-103.

(C) 2021 by the author(s). This work is licensed under a Creative Commons Attribution 4.0 International License (http://creativecommons.org/licenses/by/4.0/). Authors retain copyright of their work, with first publication rights granted to Tech Reviews Ltd. 